\title{
OPEN Fluorescent thermal shift-based method for detection of NF-KB binding to double-stranded DNA
}

\begin{abstract}
Peter D. Leitner ${ }^{1,2,3}$, Ilja Vietor ${ }^{1}$, Lukas A. Huber ${ }^{1,2} \&$ Taras Valovka $^{1,4 凶}$
The nuclear factor kappa B (NF-KB) family of dimeric transcription factors regulates a wide range of genes by binding to their specific DNA regulatory sequences. NF-KB is an important therapeutic target linked to a number of cancers as well as autoimmune and inflammatory diseases. Therefore, effective high-throughput methods for the detection of NF-KB DNA binding are essential for studying its transcriptional activity and for inhibitory drug screening. We describe here a novel fluorescence-based assay for quantitative detection of $K B$ consensus double-stranded (ds) DNA binding by measuring the thermal stability of the NF-KB proteins. Specifically, DNA binding proficient NF-KB probes, consisting of the $\mathrm{N}$-terminal p65/RelA (aa 1-306) and p50 (aa 1-367) regions, were designed using bioinformatic analysis of protein hydrophobicity, folding and sequence similarities. By measuring the SYPRO Orange fluorescence during thermal denaturation of the probes, we detected and quantified a shift in the melting temperatures $(\Delta \mathrm{Tm})$ of $\mathrm{p} 65 / \mathrm{RelA}$ and $\mathrm{p} 50$ produced by the dsDNA binding. The increase in Tm was proportional to the concentration of dsDNA with apparent dissociation constants $\left(K_{D}\right)$ of $2.228 \times 10^{-6} \mathrm{M}$ and $0.794 \times 10^{-6} \mathrm{M}$, respectively. The use of withaferin A (WFA), dimethyl fumarate (DMF) and $p$-xyleneselenocyanate ( $p$-XSC) verified the suitability of this assay for measuring dose-dependent antagonistic effects on DNA binding. In addition, the assay can be used to analyse the direct binding of inhibitors and their effects on structural stability of the protein probe. This may facilitate the identification and rational design of new drug candidates interfering with NF-KB functions.
\end{abstract}

Nuclear factor $\kappa \mathrm{B}(\mathrm{NF}-\kappa \mathrm{B})$ is a homo- or heterodimeric transcription factor formed by various Rel proteins, such as p65/RelA, p50, p52, c-Rel, and RelB ${ }^{1}$. NF- $\kappa B$ as a dimer directly interacts with the major groove of DNA recognizing $\kappa \mathrm{B}$ consensus sequences in the promoter regions of a variety of inflammatory, immune and stress response genes, thereby regulating their transcription. The binding of NF- $\mathrm{kB}$ to DNA is a tightly regulated process that is induced by different stimuli, including pathogens, cytokines, tumor promoters, and chemotherapeutic agents $^{2}$. Physiological NF- $\kappa \mathrm{B}$ response is normally transient and is characterized by the efficient termination of NF- $\kappa$ B activity by a number of signalling mechanisms ${ }^{3}$; however, in many pathological situations, such as chronic inflammation and some cancers, NF- $\mathrm{BB}$ activity becomes excessive and/or persistent, contributing to the development of disease $\mathrm{e}^{4,5}$. For this reason, the search for chemical compounds capable of inhibiting NF- $\kappa \mathrm{B}$ is considered to be a promising approach for anti-inflammatory and anti-cancer drug discovery ${ }^{6}$. To date, most of such compounds were developed to target the upstream signalling components of the NF- $\kappa B$ pathway, e.g.

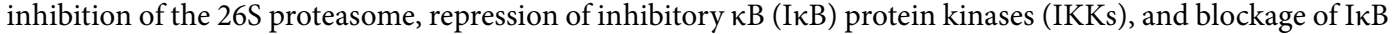
ubiquitination ${ }^{7,8}$. Because of highly pleiotropic effects of NF- $\kappa B$ inhibitors, there is a strong interest in developing new compounds targeting NF- $\kappa \mathrm{B}$ directly and thereby more specifically. Interference with the NF- $\kappa \mathrm{B}-\mathrm{DNA}$ complex formation by targeting NF- $\kappa B$ molecules is one of the most direct strategies for blocking the NF- $\kappa B$ activity. This approach raises a need for effective methods to monitor the sequence-specific binding of NF- $\kappa \mathrm{B}$ to DNA, suitable for high-throughput screening of inhibitory agents.

Numerous techniques exist for studying the interactions between NF- $\kappa B$ dimers and dsDNA. Among them, electrophoretic mobility shift assay (EMSA), DNA foot printing, filter binding and affinity chromatographybased methods are commonly used for qualitative detection of NF- $\mathrm{BB}$ binding to the DNA. These conventional and non-equilibrium techniques have limits in their application for the quantitative analysis required for the

${ }^{1}$ Institute of Cell Biology, Biocenter, Medical University of Innsbruck, Innrain 80-82, 6020 Innsbruck, Austria. ${ }^{2}$ Austrian Drug Screening Institute, ADSI, Innsbruck, Austria. ${ }^{3}$ Department of Biotechnology and Food Engineering, $\mathrm{MCl}$ Technik, Innsbruck, Austria. ${ }^{4}$ Department of Pediatrics I, Medical University of Innsbruck, Anichstrasse 35, 6020 Innsbruck, Austria. ${ }^{\circledR}$ email: taras.valovka@i-med.ac.at 
determination of binding stoichiometries, affinities and kinetics. They also have a number of other disadvantages in terms of timing, sensitivity, reproducibility, and suitability for automatic and high-throughput applications. Recently, several fluorescence-based approaches for measuring DNA-protein interactions have been developed, including "molecular beacon"-based assays, fluorescence polarization assays, protein-DNA FRET assays, and DNA-binding detection based on a modified enzyme-linked immunosorbent assay (ELISA) ${ }^{9-13}$. These techniques are often homogeneous systems allowing quantitative measurement of binding in solution; they are robust, sensitive and can be used in a high-throughput format. However, one key drawback of aforementioned methods is their specific detection of bound and unbound states of nucleic acid, requiring chemical labelling and/or processing of oligonucleotide probes by an additional enzymatic component of the reaction, e.g. exonuclease III ${ }^{11}$. The use of chemically labelled probes not only raises costs, but often limits the range of nucleic acid structures compatible with the assay. Furthermore, the presence of additional enzymatic components restricts the assay conditions and potentially complicates interpretation of results. In particular, the tested compounds might interfere with assay specific enzymes, leading to false positive screening candidates. In addition, current fluorescencebased techniques detect fluorescent signals produced exclusively by the DNA probe without monitoring the integrity (e.g. dimerization) and conformational changes of DNA-binding proteins in the reaction. This may limit the usage of such techniques in various applications, including screening for inhibitors and their validation.

A wide range of biophysical techniques allows monitoring of changes in biochemical and structural properties of proteins, caused by protein-ligand interactions. For instance, the fluorescence-based thermal shift assay (F-TSA) is routinely used for detection of protein-peptide, protein-ion or protein-drug interactions by determining changes in thermal stability of a given protein upon binding its specific ligand ${ }^{14}$. This is achieved by measuring fluorescence produced by the interaction of a specific protein dye, e.g. SYPRO Orange, with hydrophobic core residues, which become exposed during the temperature-induced protein unfolding. Fluorescence values are then used for the determination of the protein transition melting point or melting temperature $(\mathrm{Tm})$ as a measure of thermal stability. Intriguingly, F-TSA has been previously applied for the detection of DNA-mediated changes in the thermal stability of ExsD from Pseudomonas aeruginosa and herpes simplex virus type 1 (HSV-1) single stranded (ss) DNA-binding protein ICP ${ }^{15,16}$. It has been shown that random oligonucleotide ligands caused dissociation of the ExsD trimer in a sequence-independent manner, which was consistent with the loss of protein stability and reduction of melting transition point. The latest was interpreted as the evidence of a non-specific low affinity ExsD-DNA interaction, albeit not confirmed by EMSA ${ }^{15}$. In contrast, the stability of ICP8 was increased upon cooperative binding of ICP8 monomers to ssDNA oligomers of different length. We made an initial observation that short dsDNA oligomers possessing the $\kappa \mathrm{B}$ consensus sequences 5'-GGGRNYYYCC-3' (in which R is a purine, $\mathrm{Y}$ is a pyrimidine, and $\mathrm{N}$ is any nucleotide) increased the Tm of p65/RelA-specific Rel homology domain $(\mathrm{RHD})^{17}$. These observations suggested that the measurement of thermal stability could be suitable to set up an assay for detecting highly specific and sequence-dependent interactions of NF- $\kappa$ B with dsDNA.

Herein, we report the development and evaluation of a simple, robust, quantitative, high-throughput suitable method for in vitro studies of the NF- $\mathrm{BB}$ DNA-binding activity using the homogenous fluorescence-based thermal shift (F-TSA) assay with standard real-time PCR equipment. We also demonstrate its applicability and high efficiency for the identification of compounds disrupting NF- $\mathrm{kB}-\mathrm{dsDNA}$ interactions and for the simultaneous monitoring of their direct effects on the structural stability and folding of dimeric NF- $\kappa$ B proteins.

\section{Results}

Design of NF-KB protein probes and assessment of their thermal stability. The thermofluor assay with a SYPRO Orange dye is compatible with most soluble proteins that are well folded and characterized by a relatively large hydrophobic core. Intrinsically disordered proteins generate a high background fluorescence caused by fluorophore binding to the protein in its native state, interfering with the assay. To design protein probes compatible with this method, we analysed the amino acid sequence of the p65/RelA subunit of $\mathrm{NF}-\kappa \mathrm{B}$ for the presence and distribution of potentially disordered or structurally flexible segments using two different trained algorithms: SPOT-disorder and IUPred2A (http://sparks-lab.org/server/SPOT-disorder/, https ://iupred2a.elte.hu $)^{18,19}$. SPOT-disorder and IUPred2A predicted extensive segments of disordered structure (score above 0.5 ) within the region surrounding the nuclear localization signal (NLS), the linker region and the C-terminal transactivation domain (TAD): amino acids 293-304 and 312-551 (Fig. 1a,b). This correlated well with the structural studies employing CD and NMR spectroscopy that showed a random coil conformation of the C-terminal TAD ${ }^{20}$. X-ray structures from the PDB (1MY7, 2RAM, 5U01) indicated that the RHD of p65/RelA (aa 19-304) consists of two globular regions exhibiting an immunoglobulin (Ig)-like fold. These two folded regions are joined by a short, approximately 10 amino acids in length, flexible sequence and represent DNA-binding and dimerization subdomains ${ }^{21}$. Both algorithms correctly predicted a high degree of folding for the N-terminal sequence comprising residues 15-293, although IUPred2A showed that the sequence within the DNA-binding subdomain (aa 24-92) had some propensity for being unstructured. It is possible that the residues beyond this sequence are important for promoting folding, seen in the crystal structure, likely via dimerization mediated by the remaining part of RHD ${ }^{22}$. Next, we analysed the hydrophobic properties of p65/RelA using Kyte and Doolittle method ${ }^{23}$ on ExPASy Protscale (https://web.expasy.org/protscale/) (4. $^{24}$. The hydropathy plot revealed that the p65/RelA protein was moderately hydrophilic with the grand average of hydropathy (GRAVY) value of -0.463 . We also found that hydrophobic patches were evenly distributed along the protein sequence with the exception of boundary region between the structured $\mathrm{N}$-terminal and intrinsically disordered C-terminal parts. This region surrounded the NLS and was characterized by a low hydropathy score (Fig. 1c).

Based on our in-silico analysis and available structural data, we designed two different NF- $\kappa$ B protein probes for the F-TSA-based DNA-binding assay. Both probes were HIS-tagged truncated versions of the human p65/ RelA subunit consisting of either the complete RHD (p65 ${ }_{1-306}$ ) or its N-terminal DNA-binding part (p65 ${ }_{1-107}$ ) 
a
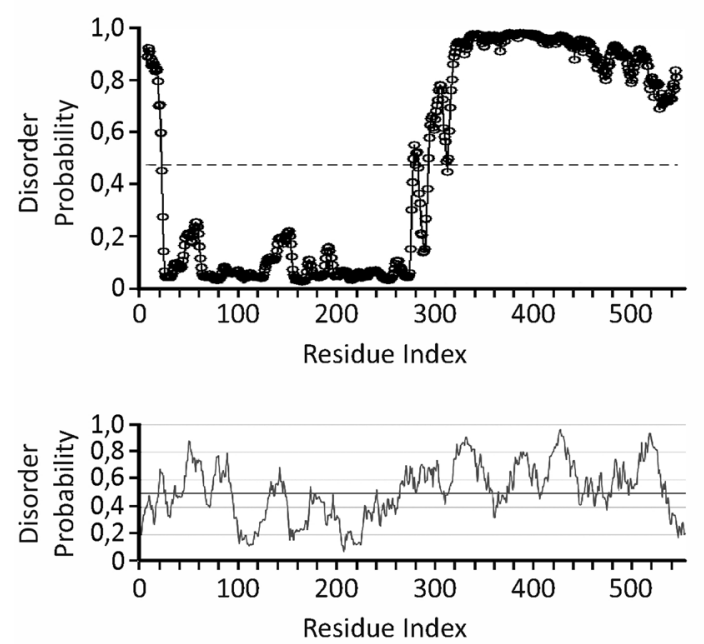

b

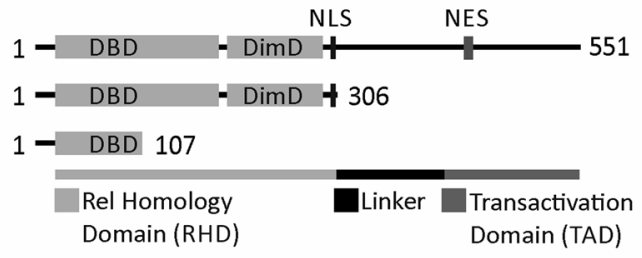

C

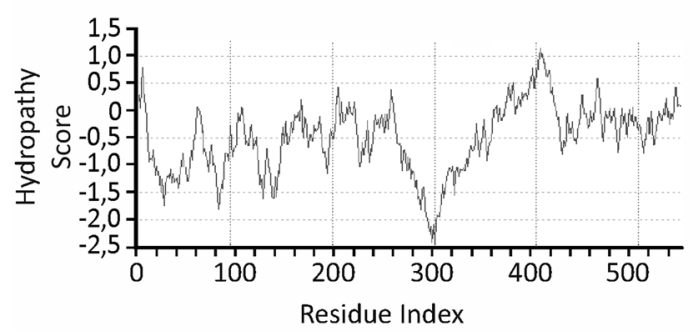

d
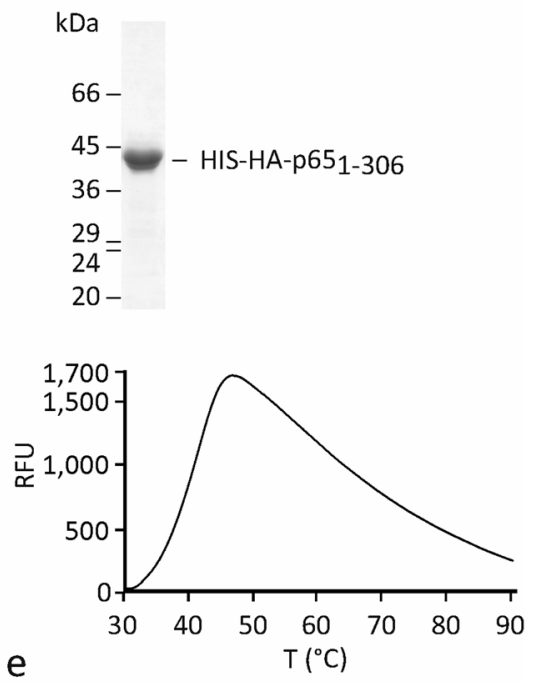

$\mathrm{kDa}$
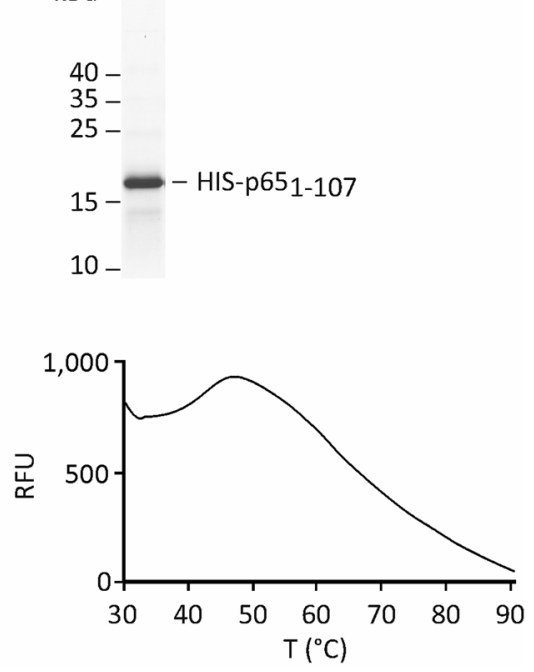

Figure 1. Design, purification and thermal stability of p65/RelA peptide probes. (a) Prediction of protein disorder using the SPOT-disorder (upper) and IUPred (lower) web servers for the p65/RelA subunit of NF-kB. The IUPred output was generated using the long disorder option. (b) Scheme of the p65/RelA protein and its deletion variants representing the NF- $\mathrm{kB}$ probes. The DNA-binding (DBD) and dimerization (DimD) subdomains, and nuclear import (NLS) and export (NES) signals are indicated. (c) The hydrophobic properties of p65/RelA were analysed using the ExPASy Protscale web server. (d,e) SDS-PAGE analysis of HIS-tagged p $65_{1-306}$ and $\mathrm{p} 65_{1-107}$ proteins expressed in E. coli and purified by affinity chromatography. The thermal stabilities of purified proteins were analysed by measuring SYPRO Orange dye fluorescence over a temperature $(\mathrm{T})$ range of $25-95^{\circ} \mathrm{C}$ using a real-time PCR thermocycler. Representative unfolding curves are shown. $R F U$ relative fluorescence unit.

(Fig. 1b). The p65 $5_{1-306}$ probe could form DNA-binding competent p65/RelA dimers as shown by EMSA ${ }^{17}$. In contrast, the p65 ${ }_{1-107}$ protein was expected to be purified as a monomer due to the lack of dimerization subdomain. Thus, it could be useful for controlling the formation and stability of p65/RelA dimers in the assay. Both proteins were Ni-NTA affinity purified from E. coli and their thermal stabilities were initially analysed using the SYPRO Orange fluorescence dye (Fig. 1d,e). Comparable amounts of p65 $5_{1-306}$ and p65 $5_{1-107}$ proteins $(0.75 \mu \mathrm{M})$ were thermally denatured in the presence of SYPRO Orange dye using a real-time PCR thermocycler. Analysis of the unfolding curves showed that $\mathrm{p} 65_{1-107}$ was characterized by a high initial fluorescence, which exhibited only a minor increase upon heating. High fluorescence background produced by $\mathrm{p} 65_{1-107}$ protein could possibly be explained by its structural instability or partially unfolded state consistent with the IUPred2A prediction. However, this prevented the further use of $\mathrm{p} 65_{1-107}$ as a probe for the F-TSA assay. Unlike the N-terminal part, the unfolding curve of $\mathrm{p} 65_{1-306}$ peptide was characterized by a low initial fluorescence that gradually increased with temperature reaching the maximal value at approx. $42.5^{\circ} \mathrm{C}$. This value was defined as the Tm of $\mathrm{p} 65_{1-306}$ under specified experimental conditions. We also used serial dilutions of $\mathrm{p} 65_{1-306}$ to evaluate the optimal amount of $\mathrm{p} 65_{1-306}$ probe for the reliable detection of protein unfolding and precise estimation of Tm in the F-TSA assay 

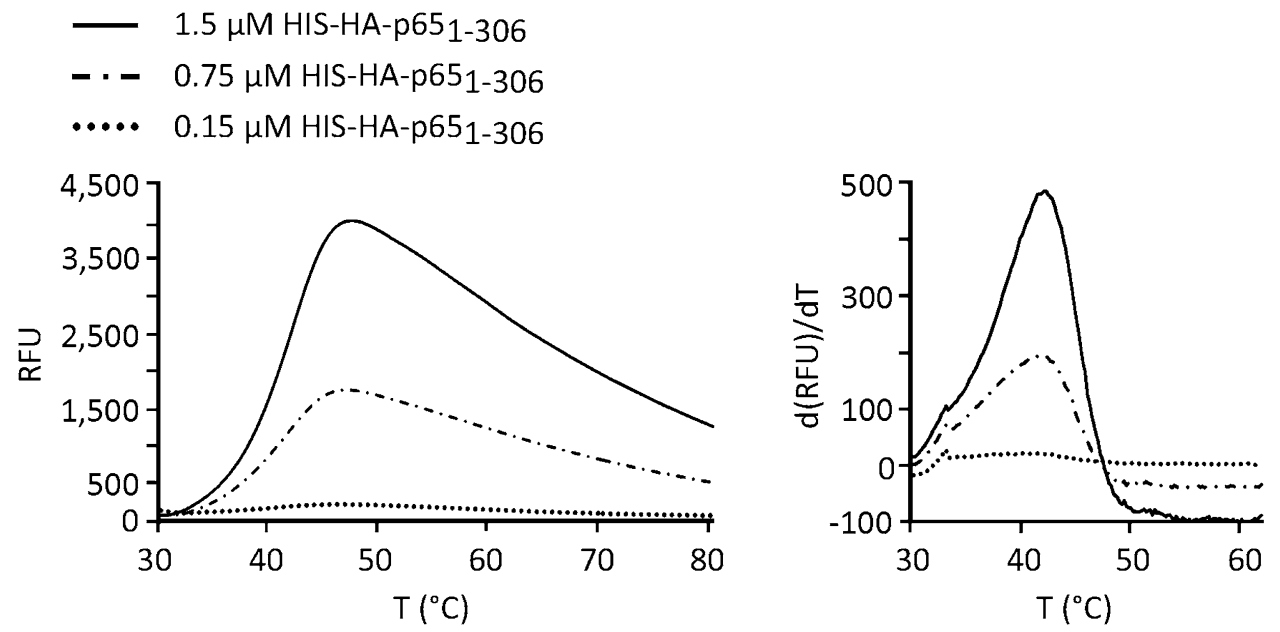

Figure 2. P65/RelA probe detection limit by using SYPRO Orange dye. The thermal denaturation was evaluated for a concentration series of $\mathrm{p} 65_{1-306}$ peptide using SYPRO Orange dye as in Fig. 1d. Representative unfolding (left) and positive derivative (d(RFU)/dT) (right) curves are shown. $R F U$ relative fluorescence unit.

(Fig. 2). We found out that $0.15 \mu \mathrm{M}$ of $\mathrm{p} 65_{1-306}$ represented the lowest limit of protein detection but was insufficient for the correct estimation of Tm whereas $0.75 \mu \mathrm{M}$ and $1.5 \mu \mathrm{M}$ concentrations produced high-intensity fluorescent signals suitable for this analysis.

RHD proteins share a high degree of similarities in their structural organization and amino acid sequences. Similar to p65, we also generated and purified HIS-tagged truncated version of the human p50 subunit consisting of the complete RHD (aa 1-367). The $\mathrm{p} 50_{1-367}$ protein was characterized by a higher Tm (approx. $44.5^{\circ} \mathrm{C}$ ) than for p65 and can be used as an alternative NF- $\kappa$ B probe in TSA-based applications (Supplementary Fig. 1).

Detection of sequence-specific dsDNA binding by measuring the thermal stability of NF-KB. Next, we tested how the thermal stability profiles of $\mathrm{p} 65_{1-306}$ and $\mathrm{p} 50_{1-367}$ proteins were affected by the presence of dsDNA either with one ( $1 \kappa \mathrm{B}$ dsDNA) or two identical $\kappa \mathrm{B}$ binding sites ( $5^{\prime}$-GGGACTTTCC- $\left.3^{\prime}\right)$ separated by four base pairs (bp) $(2 \kappa \mathrm{B}$ dsDNA). When $10 \mu \mathrm{M}$ of each of the ds oligonucleotides were incubated with $1.5 \mu \mathrm{M}$ p $65_{1-306}$ or $\mathrm{p} 50_{1-367}$ probes prior to the thermal denaturation, a shift in the protein melting temperatures was observed that raised the Tm by approx. $1-1.5^{\circ} \mathrm{C}$ to $43.5-44^{\circ} \mathrm{C}$ or $2-3{ }^{\circ} \mathrm{C}$ to $46.5-47.5^{\circ} \mathrm{C}$, respectively (Fig. 3a,b, Supplementary Fig. 1). The increase in thermal stability seen for the NF- $\kappa$ B proteins was explained by the formation of additional bonding contacts between dsDNA helix and the DNA-binding residues of RHD ${ }^{21}$. The presence of the second NF- $\kappa \mathrm{B}$-binding motif in $2 \kappa \mathrm{B}$ dsDNA had only a moderate additive effect on the increase in protein $\mathrm{Tm}$ when compared to $1 \mathrm{kB}$ dsDNA. This likely to be explained by the anti-cooperative binding of RHD dimers previously reported for dsDNA, possessing two tandemly arranged $\kappa \mathrm{B}$ sites ${ }^{25}$. To verify that the stabilization effect was solely caused by the sequence-specific binding of NF- $\kappa B$ to dsDNA, we designed an oligonucleotide duplex lacking the cognate binding sites ( $\kappa$ Bmut dsDNA). The inability of p65 ${ }_{1-306}$ dimers to bind the $\kappa$ Bmut dsDNA was confirmed by EMSA (Fig. $3 \mathrm{c}$ ). Consistent with this result, the $\kappa B m u t$ dsDNA had no detectable effect on the stability of $\mathrm{p} 65_{1-306}$ (Fig. 3a,b), indicating high specificity for the detection of $\kappa \mathrm{B}$ consensus-dependent dsDNA binding.

Next, we applied the assay for evaluating the DNA-binding activity of recombinant p $65_{1-306}$ and p50 $50_{1-367}$ proteins. For this purpose, $1.5 \mu \mathrm{M}$ of each of the recombinant proteins were incubated with different testing setups. As shown in Fig. $3 \mathrm{~d}$ and Supplementary Fig. 1, the presence of $2 \kappa B$ dsDNA increased the Tm of p65 $65_{1-306}$ and $\mathrm{p} 50_{1-367}$ in a concentration-dependent manner, resulting in an estimated $\Delta$ Tmax equal to $1.678^{\circ} \mathrm{C}$ and $2.462^{\circ} \mathrm{C}$, respectively. Considering that the $\mathrm{p} 65_{1-306^{-}}$and $\mathrm{p} 50_{1-367}$-specific dsDNA binding involved two equivalent $\kappa \mathrm{B}$ sites, the calculated dissociation constants $\left(\mathrm{K}_{\mathrm{D}}\right)$ were $2.228 \times 10^{-6} \mathrm{M}$ and $0.794 \times 10^{-6} \mathrm{M}$. This is consistent with previous reports demonstrating higher DNA-binding affinities for p50 homodimers ${ }^{26,27}$. Thus, our analysis demonstrated the feasibility of F-TSA DNA-binding assay for a quantitative evaluation of equilibrium NF- $\kappa \mathrm{B}$ dsDNA interactions.

Because different experimental tasks may require the testing of DNA binding at various temperatures, we compared the stability and dsDNA binding of $\mathrm{p} 65_{1-306}$ probe at $4{ }^{\circ} \mathrm{C}$ and $30^{\circ} \mathrm{C}$. As shown in Supplementary Fig. 2, there was no significant difference in the thermal stability of the probe incubated with or without dsDNA at $4{ }^{\circ} \mathrm{C}$ and $30^{\circ} \mathrm{C}$. This permits the testing of DNA binding in a broad range of temperatures, providing a substantial flexibility for experimental setups.

F-TSA-based analysis of dsDNA binding inhibition by NF-kB-targeting compounds. We used the known NF- $\kappa$ B inhibitors WFA and DMF to further investigate the utility of the F-TSA dsDNA-binding assay for screening and validation applications (Figs. 4, 5). Their chemical structures are shown in Figs. 4a and 5a, respectively. Both compounds interfere with the DNA-binding activity of NF- $\mathrm{BB}$, yet utilizing distinct inhibi- 


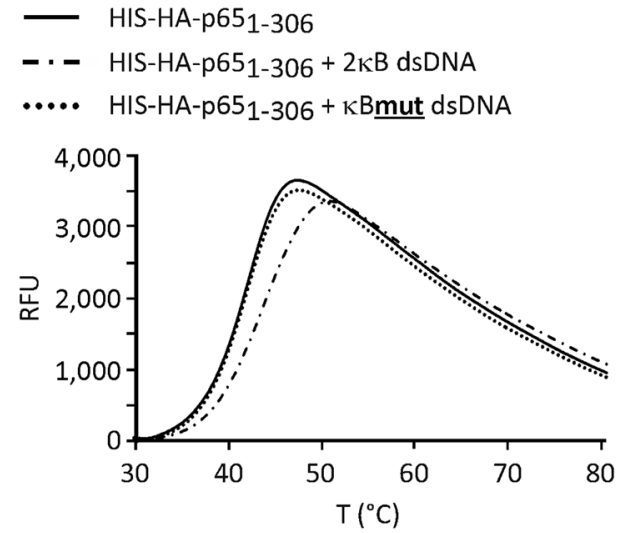

b

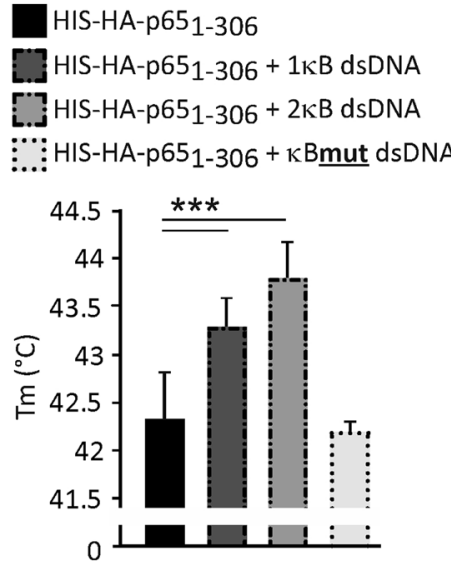

C

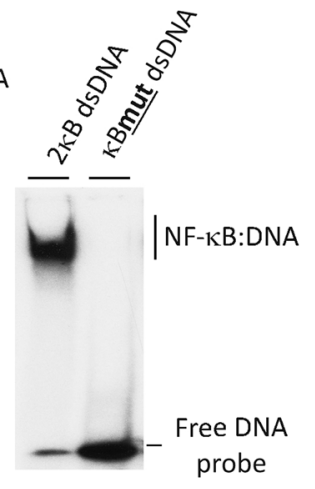

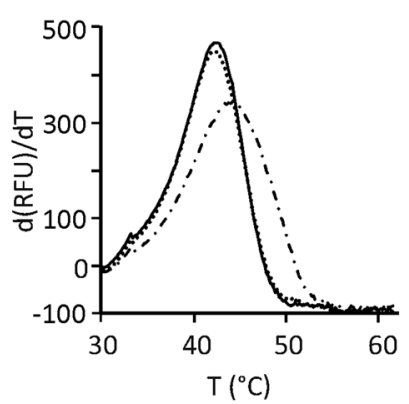

d

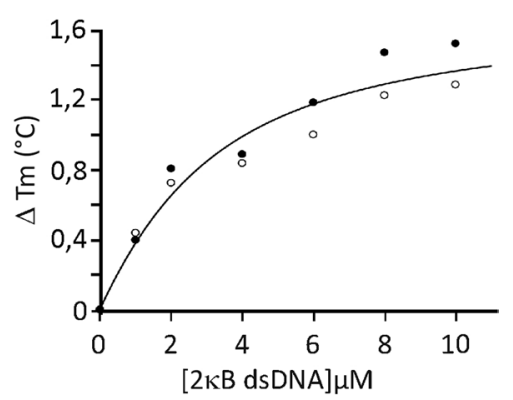

Figure 3. Detection of sequence-specific dsDNA binding to p65/RelA probe in the thermal shift assay. $(\mathbf{a}, \mathbf{b})$ The $\kappa \mathrm{B}$-dependent thermal stabilization of $\mathrm{p} 65_{1-306}$ probe in the presence of $10 \mu \mathrm{M}$ dsDNA oligomers. Representative unfolding (left) and positive derivative (d(RFU)/dT) (right) curves are shown. Midpoint temperatures of the protein-unfolding transition $(\mathrm{Tm})$ are presented as bars. Values are mean $\pm \mathrm{SD}$ of at least three independent measurements $\left({ }^{* *} p<0.001\right)$. (c) EMSA of $p 65_{1-306}$ protein $(0.5 \mu \mathrm{M})$ using ${ }^{32} \mathrm{P}$-labelled $2 \kappa \mathrm{B}$ and mutated $\kappa \mathrm{B}$ consensus oligonucleotides $\left(1 \times 10^{4} \mathrm{cpm}\right)$. (d) Thermal stability shift assessed with varying $2 \kappa \mathrm{B}$ dsDNA concentrations. $\Delta \mathrm{Tm}$, change in Tm of $\mathrm{p} 65_{1-306}$ probe caused by dsDNA. The curve is based on two separate acquisitions shown as open and closed circles.

tory mechanisms ${ }^{28,29}$. DMF covalently modifies reactive Cys38 of p65/RelA that forms a hydrogen bond with the sugar/phosphate DNA backbone, whereas WFA binds to the dimerization interface and surface residues E285 and Q287 of p65/RelA homodimer, inhibiting dimerization and DNA binding directly and allosterically. The thermal stability of p65 $5_{1-306}$ was evaluated in the presence of different concentrations of inhibitor alone or together with the $2 \mathrm{kB}$ dsDNA. We found that both tested compounds reduced the thermal stability of p65 $5_{1-306}$ dimer in a concentration-dependent manner, i.e. $24 \mu \mathrm{M}$ and $50 \mu \mathrm{M}$ WFA decreased the Tm by approx. 0.7 and $1.7^{\circ} \mathrm{C}$ (Fig. 4 b,c); $0.1 \mathrm{mM}$ and $0.28 \mathrm{mM} \mathrm{DMF}$ by approx. 0.3 and $1.1{ }^{\circ} \mathrm{C}$ (Fig. $5 \mathrm{~b}, \mathrm{c}$ ), respectively. Loss of thermal stability mediated by WFA and DMF indicated their direct binding and/or modification of p65 ${ }_{1-306}$ protein associated with destabilizing structural changes. Furthermore, the inhibitory drugs substantially reduced the thermal stabilization effect caused by the $2 \kappa \mathrm{B}$ dsDNA, indicating the interference with the DNA-binding activity of $\mathrm{p} 65_{1-306}$ protein. These effects were dose-dependent and correlated well with the WFA- and DMF-specific inhibition of DNA binding, as confirmed by the EMSA assay (Figs. $4 \mathrm{~d}, 5 \mathrm{~d}$ ). Interestingly, the indicated WFA

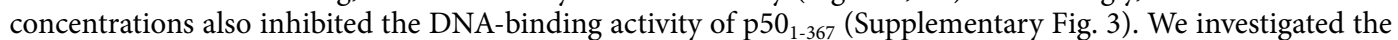
WFA-mediated inhibition of p65 and p50 proteins in more detail using a serial dilution of the inhibitor. In these experiments we found that WFA inhibited the DNA-binding activities of p65 $1_{1-306}$ and p50 $0_{1-367}$ with $\mathrm{IC}_{50}$ of approx. 16.4 $\mu \mathrm{M}$ and 19.1 $\mu \mathrm{M}$, respectively (Supplementary Fig. 3). It is possible, however, that the transactivation (TAD) domain missing in our probes may affect the WFA-mediated inhibition. Thus, we cannot exclude that the actual $\mathrm{IC}_{50}$ values differ for the intact p65 and p50 proteins. Additionally, we tested a more general inhibitor of transcription factors the organoselenium compound $p$-XSC ${ }^{30}$ and used the betaine lipid DGTS ${ }^{31}$ as a negative control. The later one acts as an anti-inflammatory agent that inhibits nitric oxide (NO) production in macrophage cells through downregulation of inducible nitric oxide synthase (iNOS). As expected, $p$-XSC 
a c

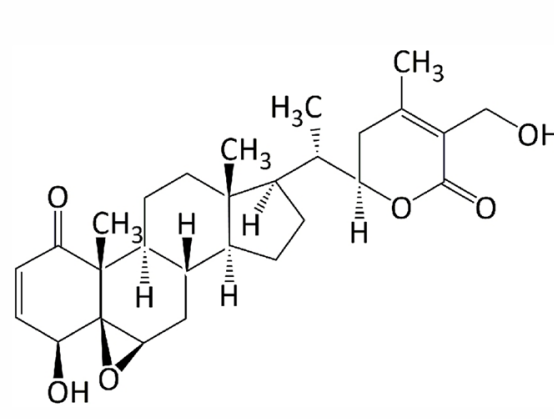

Withaferin A (WFA)
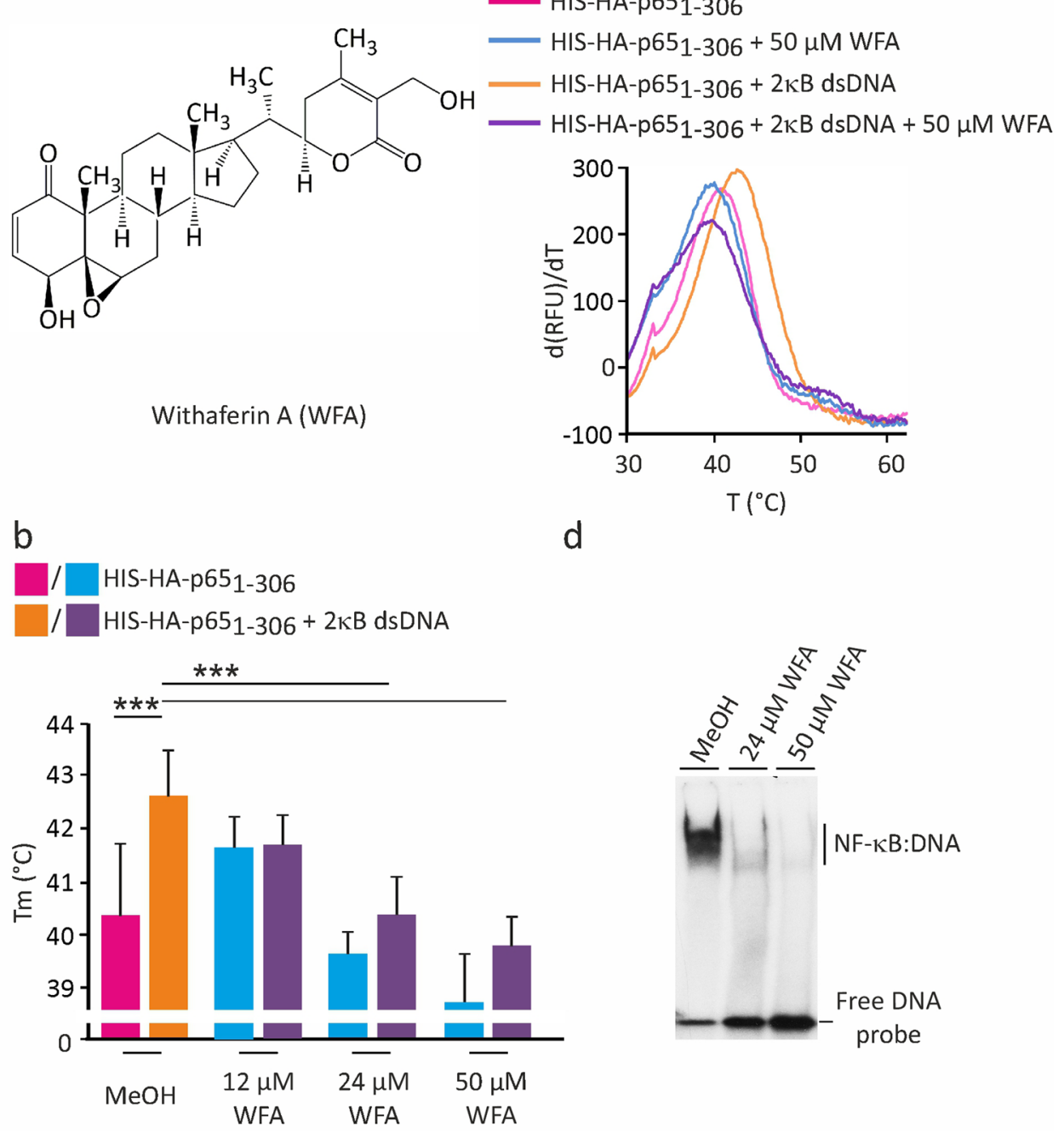

d

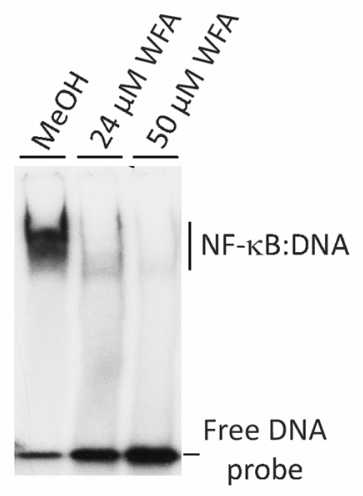

Figure 4. Effect of withaferin A on the dsDNA-induced p65/RelA thermal stability shift. (a) Chemical structure of WFA. (b,c) The thermal denaturation of p65 $5_{1-306}$ was measured in the absence and presence of $10 \mu \mathrm{M} 2 \kappa \mathrm{B}$ dsDNA and varying concentrations of WFA, as indicated. Representative derivative (d(RFU)/dT) curves are shown for untreated and treated with $50 \mu \mathrm{M}$ WFA samples. Midpoint temperatures of the proteinunfolding transition $(\mathrm{Tm})$ are presented as bars. Values are mean $\pm \mathrm{SD}$ of at least three separate measurements $\left.{ }^{* * *} p<0.001\right)$. (d) The inhibitory effect of WFA on the DNA-binding activity of p65 $5_{1-306}$ was verified by EMSA.

inhibited the dsDNA-mediated stabilization of $\mathrm{p} 65_{1-306}$ in a dose-dependent manner (Supplementary Fig. 4). In contrast, even a high concentration of DGTS showed no detectable effect on the DNA-binding activity of p65, supporting specificity of the assay (Supplementary Fig. 4). Thus, our results highlighted the amenability of the F-TSA-based DNA-binding assay for the screening of small molecules as modulators of NF- $\kappa \mathrm{B}$-specific interactions with the dsDNA.

\section{Discussion}

In this study we describe a fluorescence-based, label-free method for the quantitative detection of NF- $\kappa \mathrm{B}$ binding to $\kappa \mathrm{B}$ dsDNA using the thermal stability shift assay. This approach allowed the direct evaluation of NF- $\kappa \mathrm{B}-\mathrm{dsDNA}$ interaction by monitoring an increase in the thermal stability of protein upon sequence-specific DNA binding. Firstly, we present here a concept for the design and optimization of the recombinant NF- $\mathrm{B}$ protein probes using a selection of freely available web servers for the sequence-based structural analysis. As shown here for the $\mathrm{p} 65_{1-306}$ and $\mathrm{p} 65_{1-107}$ variants of $\mathrm{p} 65 /$ RelA protein, the evaluation of several structural parameters, including disorder probability and hydropathy index, allowed us to predict the probe suitability for the assay. Similar algorithm is likely to be useful in designing peptide probes for other DNA-binding proteins.

Secondly, we optimized the assay and verified its accuracy and sensitivity in various experimental setups. The established assay takes advantage of the high-intensity fluorescence produced upon binding of SYPRO Orange dye to exposed hydrophobic amino acid residues, enabling the detection of protein in the nanomolar range. 


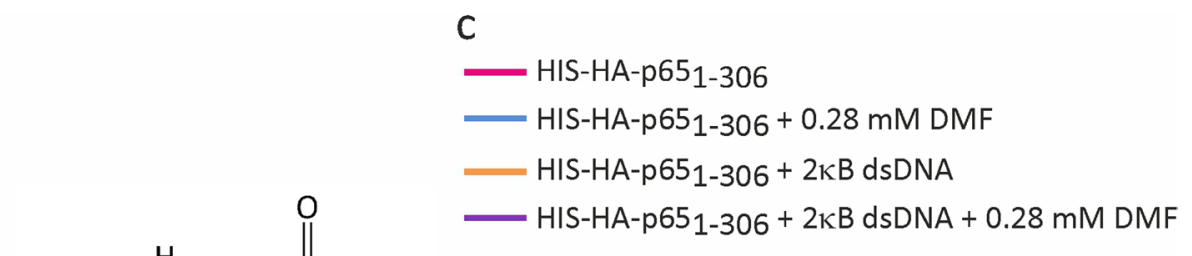

b<smiles></smiles>

Dimethyl fumarate (DMF)
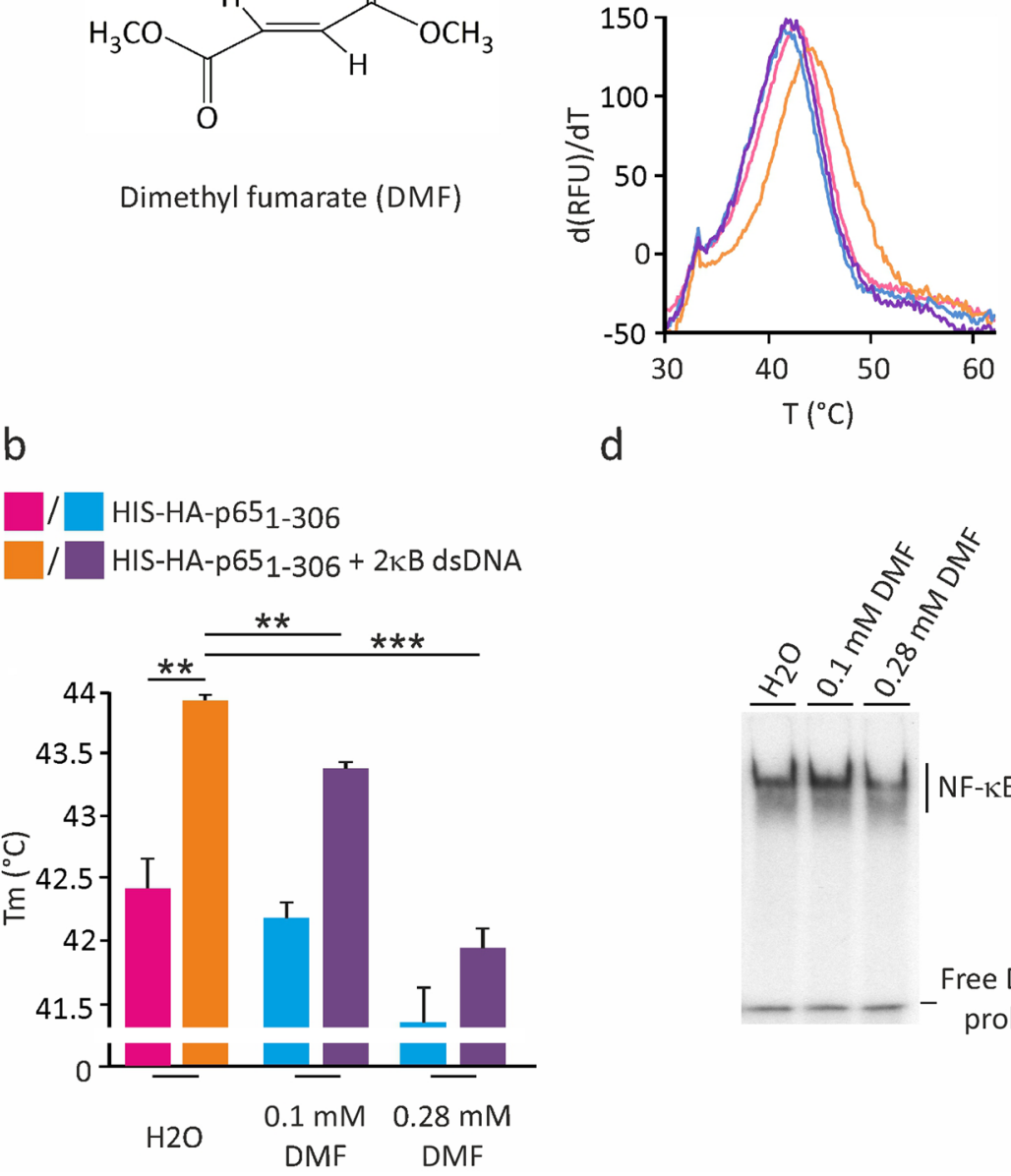

d

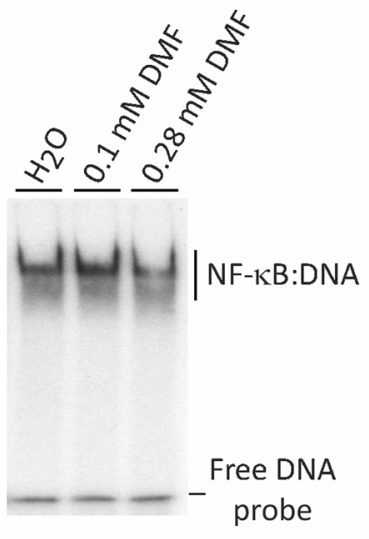

Figure 5. Dose-dependent inhibition of p65/RelA dsDNA binding by dimethyl fumarate. (a) Structure of DMF. (b,c) The thermal denaturation of $\mathrm{p}^{6} 5_{1-306}$ was evaluated as in Fig. $4 \mathrm{~b}$ with indicated concentrations of DMF. Positive derivative (d(RFU)/dT) curves are shown for control and treated with $0.28 \mathrm{mM}$ DMF samples. Midpoint temperatures of the protein-unfolding transition $(\mathrm{Tm})$ are presented as bars. Values are mean $\pm \mathrm{SD}$ of three measurements $\left({ }^{* *} p<0.01\right.$ and $\left.{ }^{* *} p<0.001\right)$. (d) EMSA analysis of $p 65_{1-306}$ DNA binding in the presence of DMF.

These protein concentrations are comparable to those used in $\mathrm{EMSA}^{25}$ and various different fluorescence-based methods ${ }^{11,32}$. The sensitivity of this assay might be further improved by using different fluorescent dyes with a different mode of binding to the protein probe. One such alternative could be the use of thiol-specific fluorochrome $\mathrm{N}$-[4-(7-diethylamino-4-methyl-3-coumarinyl)phenyl]maleimide (CPM), that modifies cysteines embedded in the protein interior, thereby triggering the emission of light ${ }^{33}$. P65 $5_{1-306}$ contained nine cysteine residues as potential modification sites for CPM, supporting the use of this "off-on" fluorescent compound in the proposed assay. Moreover, we showed that the thermal stabilization of p65 ${ }_{1-306}$ probe by the presence of $\operatorname{dsDNA}\left(\Delta \operatorname{Tm} \sim 1.5^{\circ} \mathrm{C}\right)$ was highly specific for the $\kappa \mathrm{B}$ consensus sequence with virtually no binding to mutated $\kappa \mathrm{B}$ oligos. The titration of dsDNA concentrations permitted an accurate calculation of the dissociation constants for p65 as well as for a homologous protein $\mathrm{p} 50, \mathrm{~K}_{\mathrm{D}}=2.228 \times 10^{-6} \mathrm{M}$ and $0.794 \times 10^{-6} \mathrm{M}$. The values were consistent with distinctive DNA-binding affinities previously observed for these proteins in vitro ${ }^{26,27}$. These results proved the suitability of the NF- $\kappa B$ DNA-binding assay for the equilibrium analysis and determination of basic dsDNA-binding parameters. However, one has to consider that the binding constants obtained by the F-TSA-based assay rely on the detection of DNA binding at temperatures higher than physiological ones.

Finally, we verified the suitability of this method for screening and characterization of small molecules interfering with the NF- $\kappa \mathrm{B}$ binding to DNA. The novel assay presented here measured the gradual inhibition of p65-specific Tm stabilization by dsDNA in the presence of increasing amounts of NF- $\kappa \mathrm{B}$-targeting compounds, 
i.e. withaferin A, dimethyl fumarate and p-xyleneselenocyanate. We also discovered here that WFA inhibited the DNA-binding activity of p50, suggesting its general inhibitory effect on Rel homology domain proteins. Interestingly, the WFA- and DMF-mediated inhibition correlated to a large extent with the loss of p65/RelA and p50 stabilities, suggesting structural changes introduced by these inhibitors. The structural re-arrangements of RHD upon WFA binding to the hydrophobic core domain (HCD) of p65/RelA have been previously suggested as possible explanation for its allosteric inhibitory effect, albeit missing direct experimental evidence. Our findings provide first experimental support of this hypothesis. DMF acts differently to WFA and is known to covalently modify Cys38 of p65/RelA interfering thereby with the hydrogen bond formed between this residue and the sugar/phosphate DNA backbone. The data obtained in our assay suggested that along with the H-bond formation interference, the structural changes in p65/RelA might be relevant to the DMF-specific inhibitory mechanism. Hence, our approach allows a direct and simultaneous evaluation of interactions between NF- $\mathrm{BB}$ and dsDNA as well as NF- $\kappa \mathrm{B}$ and inhibitory compounds, providing additional insights on possible interference mechanisms. We envision that our newly developed assay could be expanded to detect and characterize sequence-dependent protein-dsDNA interactions mediated also by other transcriptional factors.

\section{Methods}

Recombinant protein expression and purification. Bacterial pET28b(+) and pET21b(+) plasmids coding for HIS-tagged $\mathrm{p} 65_{1-306}$ and $\mathrm{p} 65_{1-107}$ were described previously ${ }^{17}$. The coding region of p50 (aa 1-367) was cloned into the pcDNA3.1(+)-MYC vector to produce the N-terminal MYC-tagged p50 version. The MYCtagged p50 fragment was fused to HIS-tag coding sequences by subcloning into the BamHI and XhoI sites of the pET28b(+) vector (Novagen). Recombinant proteins were expressed in Escherichia coli (E. coli) strain BL21 (DE3) CodonPlus-RIL (Stratagene) and purified by affinity chromatography on an ÄKTA Purifier System using HisTrap column (GE Healthcare). In brief, transformed bacteria were incubated in LB media at $37^{\circ} \mathrm{C}$ up to the $\mathrm{OD}_{600}=0.8$ and then induced by $0.3 \mathrm{mM}$ IPTG for $72 \mathrm{~h}$ at $4{ }^{\circ} \mathrm{C}$. Bacteria were centrifuged at $9,000 \times g$ for $20 \mathrm{~min}$ at $4{ }^{\circ} \mathrm{C}$. The bacterial pellets were resuspended in ice-cold E. coli $\mathrm{LB}$ buffer $(50 \mathrm{mM}$ Tris- $\mathrm{HCl} \mathrm{pH} \mathrm{7.5,500} \mathrm{mM}$ $\mathrm{NaCl}, 5 \%$ glycerol, $0.5 \% \mathrm{NP}-40,40 \mathrm{mM}$ imidazole, $1 \mathrm{mM}$ PMSF, $2 \mathrm{mM} \beta$-mercaptoethanol) and lysed using the French Press (HTU-DIGI-F-Press F-013, Heinemann) at 1,300 psi. To reduce viscosity, cell extracts were supplemented with $1.7 \mu \mathrm{g} / \mathrm{ml}$ DNase I and $0.3 \mathrm{mM} \mathrm{MgCl}_{2}$ and incubated for $35 \mathrm{~min}$ on ice. The samples were then clarified by centrifugation at $18,000 \times g$ for $20 \mathrm{~min}$ at $4{ }^{\circ} \mathrm{C}$ and subsequently loaded onto a $1 \mathrm{ml}$ HisTrap column equilibrated in $E$. coli LB2 buffer. Column was washed thoroughly with washing buffer ( $50 \mathrm{mM}$ Tris- $\mathrm{HCl} \mathrm{pH}$ 7.5, $500 \mathrm{mM} \mathrm{NaCl}, 5 \%$ glycerol, $0.5 \% \mathrm{NP}-40,60 \mathrm{mM}$ imidazole, $2 \mathrm{mM} \beta$-mercaptoethanol) followed by washing with the same buffer without NP-40. Bound proteins were eluted with elution buffer ( $50 \mathrm{mM}$ Tris- $\mathrm{HCl} \mathrm{pH}$ 7.5, $500 \mathrm{mM} \mathrm{NaCl}, 5 \%$ glycerol, $500 \mathrm{mM}$ imidazole, $2 \mathrm{mM} \beta$-mercaptoethanol) at a flow rate of $0.5 \mathrm{ml} / \mathrm{min}$ and dialyzed overnight against the same buffer without imidazole. Protein purity was checked by $10 \%$ and $15 \%$ SDS-PAGE and concentrations were determined by using the Coomassie Plus Protein Assay Reagent (Thermo Scientific). Protein aliquots were stored in liquid nitrogen.

Electrophoretic mobility shift assay. Complementary oligonucleotides were synthesized and HPLCpurified by Sigma-Aldrich. Oligomer duplexes were prepared by mixing $100 \mathrm{pmol}$ of each of the two complementary oligonucleotides in a total volume of $50 \mu \mathrm{l}$ of annealing buffer $(10 \mathrm{mM}$ Tris $\mathrm{HCl} \mathrm{pH} 8.0,5 \mathrm{mM} \mathrm{MgCl}$, $65 \mathrm{mM} \mathrm{KCl} 0.5 \mathrm{mM}$ EDTA, $1 \mathrm{mM}$ DTT). After $3 \mathrm{~min}$ incubation at $95^{\circ} \mathrm{C}$, the samples were left to form oligomer duplexes while gradually cooling to room temperature. dsDNA oligomers were $5^{\prime}-{ }^{32} \mathrm{P}$-labeled with T4 DNA polynucleotide kinase (New England Biolabs) and $\left[\gamma^{-32} \mathrm{P}\right]$ ATP (Perkin Elmer, 3,000 Ci/mmol) followed by removal of the excess of radioactive ATP using $\mathrm{LiCl} /$ ethanol precipitation. Recombinant $\mathrm{p} 65_{1-306}$ protein $(0.5 \mu \mathrm{M})$ was incubated in EMSA buffer containing $10 \mathrm{mM}$ Tris $\mathrm{HCl} \mathrm{pH} \mathrm{7.5,} 0.5 \mathrm{mM}$ EDTA, $65 \mathrm{mM} \mathrm{KCl}, 5 \mathrm{mM} \mathrm{MgCl} 2,1 \mathrm{mM}$ DTT, $100 \mu \mathrm{g} / \mathrm{mL}$ BSA, $10 \%$ glycerol, $50 \mathrm{ng} / \mu \mathrm{l}$ poly $(\mathrm{dI}-\mathrm{dC})$, and ${ }^{32} \mathrm{P}-$ labeled ds oligonucleotide $(2 \mathrm{\kappa B}$ dsDNA: 5'-AATTCGGGACTTTCCCGTCGGGACTTTCC-3'; кBmut dsDNA: 5'-AGCTCGCTATTAGACAGCTGC TATTAGACTGCA- $3^{\prime}$ ) for $45 \mathrm{~min}$ at $30^{\circ} \mathrm{C}$. Protein-DNA complexes were resolved by native $4 \%$ PAGE and visualized by autoradiography.

Fluorescence-based thermal shift assay. The thermal shift assays were performed using the PikoReal 96 Real-Time PCR System (Thermo Scientific) melting curve program with a temperature increment of $0.2^{\circ} \mathrm{C}$ and a temperature range of $25-95^{\circ} \mathrm{C}$. All reactions were incubated in a $25 \mu \mathrm{l}$ final volume and assayed in 96 -well plates using 1:1,000 dilution of 5,000 $\times$ SYPRO Orange stock solution (Sigma-Aldrich) and indicated concen-

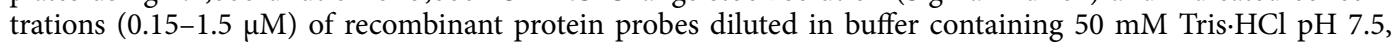
$225 \mathrm{mM} \mathrm{NaCl}$, and $2.25 \%$ glycerol. The $1 \kappa \mathrm{B}$ (AGTTGAGGGGACTTTCCCAGGC), $2 \kappa \mathrm{B}$ and $\kappa B$ mut dsDNA oligomers $(1-10 \mu \mathrm{M})$ were added to reaction to assess the DNA binding-dependent thermal stabilization of proteins. Oligomers and inhibitors (WFA dissolved in methanol; DMF dissolved in $\mathrm{H}_{2} \mathrm{O}$ (Sigma-Aldrich)) were incubated with proteins at $4{ }^{\circ} \mathrm{C}$ for 25 min prior to acquiring the melting curves. 1,4-phenylene-bis(methylene) selenocyanate ( $p$-XSC) (Abcam) and diacylglyceryl- N, N, N-trimethylhomoserine (DGTS) (Sigma-Aldrich) were dissolved in DMSO and incubated with the $\mathrm{p} 65_{1-306}$ probe at ambient temperatures for 30 min prior to the analysis. Positive derivative $(\mathrm{d}(\mathrm{RFU}) / \mathrm{dT})$ curves were built and the midpoint temperatures of the proteinunfolding transition (Tm) were estimated using the PikoReal 96 Real-Time PCR System software (Thermo Scientific).

Data analysis. Results are presented as mean \pm SD for variations between separate measurements. Statistical comparisons were calculated using the Student $t$ test. $P$ values are denoted as follows: ${ }^{\star} P<0.05,{ }^{*} P<0.01$, and ${ }^{\star * *} P<0.001$. $K_{D}$ determination was obtained by plotting the change in $\operatorname{Tm}(\Delta \mathrm{Tm})$ as a function of dsDNA 
concentrations ([dsDNA] or [D]). To fit the parameters, the curve fit function from the Python 3.5 library Scipy Optimize was applied. Equation $\Delta T m=\frac{\left(\Delta T_{\max }+[\mathrm{D}]+\mathrm{K}_{D}\right)-\sqrt{\left(\Delta T_{\max }+[\mathrm{D}]+\mathrm{K}_{D}\right)^{2}-4 \Delta T_{\max }[D]}}{2}$ was used to estimate $\Delta \mathrm{T}_{\max }$ and $\mathrm{K}_{\mathrm{D}}$. Nonlinear regression and sigmoidal dose-response curves (GraphPad PRISM8) were used to calculate $\mathrm{IC}_{50}$ values.

Received: 3 June 2020; Accepted: 7 January 2021

Published online: 27 January 2021

\section{References}

1. Hoffmann, A. \& Baltimore, D. Circuitry of nuclear factor kappaB signaling. Immunol. Rev. 210, 171-186 (2006).

2. Pahl, H. L. Activators and target genes of Rel/NF-kappaB transcription factors. Oncogene 18, 6853-6866 (1999).

3. Renner, F. \& Schmitz, M. L. Autoregulatory feedback loops terminating the NF-kappaB response. Trends Biochem. Sci. 34, 128-135 (2009).

4. Courtois, G. \& Gilmore, T. D. Mutations in the NF-kB signalling pathway: Implications for human disease. Oncogene 25, 6831-6843 (2006).

5. Ben-Neriah, Y. \& Karin, M. Inflammation meets cancer, with NF- $\kappa B$ as the matchmaker. Nat. Immunol. 12, 715-723 (2011).

6. Gilmore, T. D. \& Herscovitch, M. Inhibitors of NF-kappaB signaling: 785 and counting. Oncogene 25, 6887-6899 (2006).

7. Calzado, M. A., Bacher, S. \& Schmitz, M. L. NF-kappaB inhibitors for the treatment of inflammatory diseases and cancer. Curr. Med. Chem. 14, 367-376 (2007).

8. Freitas, R. H. C. N. \& Fraga, C. A. M. NF- $\kappa$ B-IKK $\beta$ pathway as a target for drug development: Realities, challenges and perspectives. Curr. Drug Targets 19, 1933-1942 (2018).

9. Heyduk, T. \& Heyduk, E. Molecular beacons for detecting DNA binding proteins. Nat. Biotechnol. 20, 171-176 (2002).

10. Currie, S. L. et al. Development of high-throughput screening assays for inhibitors of ETS transcription factors. SLAS Discov. 24, 77-85 (2019).

11. Wang, J., Li, T., Guo, X. \& Lu, Z. Exonuclease III protection assay with FRET probe for detecting DNA-binding proteins. Nucleic Acids Res. 33, e23 (2005).

12. Chen, Z., Ji, M., Hou, P. \& Lu, Z. Exo-Dye-based assay for rapid, inexpensive, and sensitive detection of DNA-binding proteins. Biochem. Biophys. Res. Commun. 345, 1254-1263 (2006).

13. Renard, P. et al. Development of a sensitive multi-well colorimetric assay for active NFkappaB. Nucleic Acids Res. 29, E21 (2001).

14. Grøftehauge, M. K., Hajizadeh, N. R., Swann, M. J. \& Pohl, E. Protein-ligand interactions investigated by thermal shift assays (TSA) and dual polarization interferometry (DPI). Acta Crystallogr. D. Biol. Crystallogr. 71, 36-44 (2015).

15. Bernhards, R. C., Jing, X., Vogelaar, N. J., Robinson, H. \& Schubot, F. D. Structural evidence suggests that antiactivator ExsD from Pseudomonas aeruginosa is a DNA binding protein. Protein Sci. 18, 503-513 (2009).

16. Rupesh, K. R., Smith, A. \& Boehmer, P. E. Ligand induced stabilization of the melting temperature of the HSV-1 single-strand DNA binding protein using the thermal shift assay. Biochem. Biophys. Res. Commun. 454, 604-608 (2014).

17. Reintjes, A. et al. Asymmetric arginine dimethylation of RelA provides a repressive mark to modulate TNFa/NF- $\kappa \mathrm{B}$ response. Proc. Natl. Acad. Sci. USA 113, 4326-4331 (2016).

18. Hanson, J., Yang, Y., Paliwal, K. \& Zhou, Y. Improving protein disorder prediction by deep bidirectional long short-term memory recurrent neural networks. Bioinformatics 33, 685-692 (2017).

19. Dosztányi, Z. Prediction of protein disorder based on IUPred. Protein Sci. 27, 331-340 (2017).

20. Schmitz, M.L. et al. Structural and functional analysis of the NF-kappa B p65 C terminus. An acidic and modular transactivation domain with the potential to adopt an alpha-helical conformation. J. Biol. Chem. 269, 25613-25620 (1994).

21. Chen, Y. Q., Ghosh, S. \& Ghosh, G. A novel DNA recognition mode by the NF-kappa B p65 homodimer. Nat. Struct. Biol. 5, 67-73 (1998).

22. Ghosh, G., Wang, V. Y., Huang, D. B. \& Fusco, A. NF- $\kappa$ B regulation: Lessons from structures. Immunol. Rev. 246, 36-58 (2012).

23. Kyte, J. \& Doolittle, R. F. A simple method for displaying the hydropathic character of a protein. J. Mol. Biol. 157, 105-132 (1982).

24. Gasteiger, E. et al. Protein identification and analysis tools on the ExPASy server. In The proteomics protocols handbook (ed. Walker, J. M.) 571-607 (Humana Press, 2005).

25. Mulero, M. C. et al. DNA-binding affinity and transcriptional activity of the RelA homodimer of nuclear factor $\kappa \mathrm{B}$ are not correlated. J. Biol. Chem. 292, 18821-18830 (2017).

26. Phelps, C. B., Sengchanthalangsy, L. L., Malek, S. \& Ghosh, G. Mechanism of kappa B DNA binding by Rel/NF-kappa B dimers. J. Biol. Chem. 275, 24392-24399 (2000).

27. Siggers, T. et al. Principles of dimer-specific gene regulation revealed by a comprehensive characterization of NF- $\kappa \mathrm{B}$ family DNA binding. Nat. Immunol. 13, 95-102 (2011).

28. Kastrati, I. et al. Dimethyl fumarate inhibits the nuclear factor $\kappa \mathrm{B}$ pathway in breast cancer cells by covalent modification of $\mathrm{p} 65$ protein. J. Biol. Chem. 291, 3639-3647 (2016)

29. Ashkenazi, S. et al. Novel allosteric mechanism of NF- $\kappa$ B dimerization and DNA binding targeted by an anti-inflammatory drug. Mol. Cell. Biol. 36, 1237-1247 (2016).

30. Youn, B. W., Fiala, E. S. \& Sohn, O. S. Mechanisms of organoselenium compounds in chemoprevention: Effects on transcription factor-DNA binding. Nutr. Cancer 40, 28-33 (2001).

31. Banskota, A. H., Stefanova, R., Sperker, S. \& McGinn, P. J. New diacylglyceryltrimethylhomoserines from the marine microalga Nannochloropsis granulata and their nitric oxide inhibitory activity. J. Appl. Phycol. 25, 1513-1521 (2013).

32. Ma, D. L. et al. A highly selective, label-free, homogenous luminescent switch-on probe for the detection of nanomolar transcription factor NF-kappaB. Nucleic Acids Res. 39, e67 (2011).

33. Ayers, F. C., Warner, G. L., Smith, K. L. \& Lawrence, D. A. Fluorometric quantitation of cellular and nonprotein thiols. Anal. Biochem. 154, 186-193 (1986).

\section{Acknowledgements}

We thank Joel Thormeier for helping with the data analysis. Theresia Dunzendorfer-Matt for helpful discussions and comments. This work was supported by grants from the Austrian Science Fund (P32608 to L.A.H. and P24251 to T.V.). 


\section{Author contributions}

L.A.H. and T.V. conceived the experimental part; P.L. and T.V. performed the experiments; P.L., I.V., L.A.H. and T.V. analysed the data; P.L. and T.V. prepared the figures; T.V. wrote the main text of the manuscript; I.V. and L.A.H contributed to writing. All authors reviewed the manuscript.

\section{Competing interests}

The authors declare no competing interests.

\section{Additional information}

Supplementary Information The online version contains supplementary material available at https://doi. org/10.1038/s41598-021-81743-1.

Correspondence and requests for materials should be addressed to T.V.

Reprints and permissions information is available at www.nature.com/reprints.

Publisher's note Springer Nature remains neutral with regard to jurisdictional claims in published maps and institutional affiliations.

Open Access This article is licensed under a Creative Commons Attribution 4.0 International License, which permits use, sharing, adaptation, distribution and reproduction in any medium or format, as long as you give appropriate credit to the original author(s) and the source, provide a link to the Creative Commons licence, and indicate if changes were made. The images or other third party material in this article are included in the article's Creative Commons licence, unless indicated otherwise in a credit line to the material. If material is not included in the article's Creative Commons licence and your intended use is not permitted by statutory regulation or exceeds the permitted use, you will need to obtain permission directly from the copyright holder. To view a copy of this licence, visit http://creativecommons.org/licenses/by/4.0/.

(C) The Author(s) 2021 